\title{
Effects of Biomass Fuel on Child Acute Respiratory Infections in Rural Areas of Cameroon and Gabon
}

\author{
Loty Pierre Jean-Daniel
}

IFORD CARE-IFA Local Research Group, Cameroon

Copyright $\subset 2016$ by authors, all rights reserved. Authors agree that this article remains permanently open access under the terms of the Creative Commons Attribution License 4.0 International License

\begin{abstract}
Use of biomass cooking fuel is a known risk factor of child Acute Respiratory Infections (ARI). However, studies so far did not focus on rural areas where biomass fuel use is common. The purpose of this study was to measure the effect of biomass fuel on child ARI in rural areas of Cameroon and Gabon. The analysis was based on DHS national surveys. Logistic regression helped to estimate the risk of suffering from ARI among rural children living in households using only biomass fuel compared to children living in households using a mix of gas and biomass fuel, after controlling for several confounders. In both countries, the relationship was significant, although ARI prevalence in Gabon was twice higher. In Cameroon, the effect was stronger and regional differentials were striking, rural children from the North West region being 23 times more affected than those from rural areas of Littoral.
\end{abstract}

Keywords Biomass Fuel, Acute Respiratory Infections

\section{Introduction}

Biomass fuel mainly refers to wood used as source of domestic energy. Ezzati et al. [2] estimated that in developing countries, two billion people use biomass fuel for cooking or heating. The vast majority of biomass fuel users live in rural areas. Therefore, biomass fuel use typically is a rural phenomenon. Moreover, levels of biomass fuel use vary greatly between regions within countries and between countries. In this regard, Cameroon and Gabon show different patterns. Cleaner sources of domestic energy such as LPG (Liquid Petroleum Gas) are widely used in Gabon, an oil rich country of 1.6 million inhabitants [18]. In contrast, Cameroon is home to a larger population (21.7 million [19]), but the country's oil resources are limited and rural households heavily rely on cheaper firewood. [11]

Indeed, the economic situation in Gabon is a factor behind the greater use of LPG. The GDP per capita in this country was estimated at $\$ 10,772$ in 2014, one of the highest rates in Africa [20]. With a GDP per capita of $\$ 1,407$, Cameroon's rural households have less access to relatively more expensive sources of domestic energy (electricity or LPG).

It is relevant to mention the role of the natural environment in connection with biomass fuel use. Thus, Gabon features an equatorial climate with an extensive system of rainforests covering $85 \%$ of the country [18]. As a result, wood is readily available as source of energy for cooking or heating. The climate in the southern part of Cameroon is much like Gabon's, with rural livelihoods revolving around forest products, especially wood. In the northern Sahel where savanna vegetation is predominant, people also rely on biomass fuel for domestic activities. In $2011,98 \%$ of rural children in Sahelian regions lived in biomass-fuel-using homes [11]).

Although very cheap, biomass fuel is the worst option as source of domestic energy. For a fact, biomass fuel use is a leading cause of indoor air pollution in Africa. This fuel has been ranked last on the energy ladder as far as cleanliness is concerned. [17] Besides, very few households use secured woodstoves with chimneys $(0.13 \%$ of households in Cameroon according to the $2011 \mathrm{CDHS})$, thus aggravating biomass fuel pollution. Health threatening pollutants emitted include inhalable particulate matter, carbon monoxide, nitrogen oxides, formaldehyde, benzene, 1,3 butadiene, and polycyclic aromatic hydrocarbons. [5]

It is also of interest that children have the habit of flocking into kitchens while food is boiling, thus increasing the likelihood of overcrowding at combustion site. Coupled with poor ventilation and the habit of fanning the flames by blowing at close range, exposure to these pollutants could be very severe. Typically, nursing mothers take little precaution while cooking with their babies on their backs [7], thus the higher risk incurred by women and young children [6].

Caution is in order when carrying out domestic activities since smoke emitted by cooking or heating with biomass fuel can affect, not only the eyes (cataract, blindness), but also the respiratory ways, thus aggravating the risk of Acute Respiratory Infections (ARI), Asthma, Chronic Obstructive Pulmonary Disease (COPD) and Tuberculosis. [5] ARI is noteworthy as it causes the death of five million people worldwide. [8] As far as African children are concerned, 
ARI has been regularly ranked throughout the last decade among the top three diseases, along with malaria and diarrhea. $[11,12,13,14]$ Therefore, understanding risk factors associated with ARI can contribute to policy design aiming to achieve Sustainable Development Goals, especially Goal 3, Target 2 (child mortality).

Heath issues affecting children are critical in Africa because fertility levels are barely declining [15], leading to a large proportion of children in the population. Educational levels are low, especially among women, thus aggravating the exposure of children born to unschooled mothers as these have less access to healthcare information. Furthermore, the problem is felt even more severely in rural areas where fertility is higher and educational levels are lower. Although Gabon reports higher levels of schooling, rural areas in both countries face tougher conditions.

Cameroon and Gabon use health policy frameworks inspired by French administrative tradition. Still, Cameroon presents some peculiarities due to mixed influences from German, English and French colonial rules [21]. Another factor aiming at policy harmonization is the Central African Economic and Monetary Community (CEMAC), a regional organization setting policy guidelines affecting the two countries. International health agencies at CEMAC level also tend to streamline health procedures and practices, including regional offices of WHO (World Health Organization), UNICEF (United Nations Children's Fund), Plan International, UNDP (United Nations Development Programme). Generally, Cameroon and Gabon suffer lack of adequate health facilities, especially in rural areas where trained medical personnel are scarce, the medical supply chain is deficient and people generally have limited financial means to get adequate treatment for their sick children.

\section{Literature Review and Theoretical Framework}

Besides biomass fuel, many studies have identified other factors linked to ARI, including climate, seasonality, overcrowding, environmental tobacco smoke, child nutritional status and house ventilation. [9] As a matter of fact, many studies exploring the association between biomass fuel and ARI in Africa have already been conducted (Kenya, Tanzania and Zimbabwe). For instance, in Kenya, a follow-up study was developed and a causal relationship was evidenced. [2] In Tanzania and Zimbabwe, DHS (Demographic and Health Survey) were used, leading to varying results.

In the case of Zimbabwe, children from households using biomass fuel were more exposed to ARI than children from households using cleaner energy (LPG, electricity) after controlling for several confounding variables. [3] However, in Tanzania, the measurement performed between children from households using biomass fuel and those using charcoal and kerosene did not give clear results (use of LPG or electricity was not common in Kenya when the study was conducted in 2005). The study surmised that biomass fuel as well as charcoal and kerosene were equally unhealthy, thus promoting the use of LPG or electricity. [10]

In the particular context of the CEMAC sub-region, the relationship between biomass fuel and ARI remained understudied. Additionally, studies conducted in Southern Africa were all based on older generations of DHS surveys. With the advent of DHS VI surveys (2008-2013), additional questions were asked, providing critical details related to ARI symptoms (pain in the chest) and exposure to cooking smoke (households using separate room as kitchen or cooking in separate buildings).

Moreover, no study so far featured a comparative analysis of biomass fuel effects on ARI among children living in different countries. As a matter of fact, the scale, gravity or severity of this health issue is seldom identical from country to country. Furthermore, studies generally include both urban and rural areas in the analysis. However, data show that the rural context is more conducive to biomass fuel use. According DHS surveys, around $70 \%$ of biomass fuel users live in rural areas in Cameroon and Gabon. Last but not least, the author of this study lived in rural areas of Cameroon where he personally was affected by this serious issue and determined to fight it off.

In view of the foregoing, this study focused on testing the hypothesis that children from households using only biomass fuel were more predisposed to ARI than those from households using a mix of gas and biomass fuel in rural areas of Cameroon and Gabon.

\section{Data and Methods}

\subsection{Survey Design}

The analysis was based on data from Cameroon and Gabon Demographic and Health Surveys conducted respectively in 2011 and 2012 (2011 CDHS and 2012 GDHS). Information were collected on 11732 (resp. 6 067) children under five born to 15426 (resp. 8 422) women age 15-49 living in 14214 (resp. 9 755) households comprised in a countrywide sample representing all 10 regions (resp. 09 provinces) of Cameroon (resp. Gabon). Since this study targets rural children, a specific rural dataset was extracted from the original children dataset. As a result, 5821 (resp. 1 952) rural children, selected in Cameroon (resp. Gabon), make up the sample for this analysis.

The DHS survey was implemented by the Cameroon National Institute of Statistics (resp. Gabon General Directorate of Statistics). In both countries, DHS survey objective was to collect socioeconomic and health information, including household characteristics, fertility levels and preferences, awareness and use of family planning methods, childhood mortality, maternal and child health, breast feeding practices, antenatal care, childhood immunization and diseases, nutritional status of young children and women, malaria prevention and treatment, 
women status, female circumcision, sexual activity, and knowledge and behavior regarding HIV/AIDS and other sexually transmitted diseases (2011 CDHS and 2012 GDHS Reports). The rich set of variables collected is helpful for conducting various multivariable analyses needing several confounding variables. Both countries used DHS VI methodology with two-stage cluster sample and an overall response rate of $99.0 \%$ (resp. $99.3 \%$ ).

In the first stage, 580 (resp. 336) enumeration areas were selected in Cameroon (resp. Gabon) using probability proportional to size sampling (the size of the enumeration area being the number of households). In the second stage, households were selected using equal probability systematic sampling, based on an updated listing of households obtained from underlying census frameworks. Data collection procedures were pre-tested and training was provided for the field staff in Cameroon (resp. Gabon) over a 3-week period (resp. 6-week period) in October 2009 (resp. November 2011 - January 2012). Cameroon 2011 DHS Report (CDHS) and Gabon 2012 DHS Report (GDHS) provide all details concerning survey design, management and data quality.

\subsection{Questionnaires and Data Collection}

In both countries, three questionnaires were designed respectively for households, women and men, reflecting DHS model questionnaires. Various State and non-governmental stakeholders contributed to frame the questionnaires. Procedures and questionnaires for standard DHS surveys have been reviewed and approved by the ICF International Institutional Review Board as well as the National Ethical Committees in Cameroon and Gabon.

Additionally, trained nurses were involved in the data collection process. Interviews were conducted only when the respondents provided voluntary informed consent. Moreover, experienced field reviewers verified questionnaire logic and coherence. Independent interviews helped to confirm that questions were asked accurately. High level field visits were carried out by survey supervisors to monitor data quality.

Indeed, the standard DHS surveys methodology used in both countries guarantees the comparability of data from Cameroon and Gabon, thus adding credibility to the results of this comparative analysis.

\subsection{Dependent Variable}

All mothers age 15-49, with children born during the 5 year period preceding the survey, were eligible to questions concerning the respiratory health of children under five years. For each child under five years, the mother was asked if the child had cough in the two week period preceding the survey. For children who had suffered from cough, the mother was additionally asked if the child, when ill with cough, breathed faster than usual with short, rapid breaths. If the child both suffered from cough and short, rapid breaths, the mother was asked if the child had a problem in the chest or a blocked or running nose. If the child had a problem in the chest, it was an indication that he had a pulmonary infection (pneumonia). The 2011 CDHS (resp. 2012 GDHS) categorized children who suffered from cough, accompanied with with short and rapid breathing, coupled with a problem in the chest, at any time during the two week period preceding the survey, as having ARI. This reported occurrence of ARI was the response variable in our study. It should be noted that these questions were culturally acceptable. The Multiple Indicator Cluster Surveys (MICS) methodology used in this data collection process takes into account issues related to respondent culture. Specifically, pre-testing is used to "identify any misinterpretations or cultural objections to the questions" [16].

\subsection{Predictor Variable}

The DHS VI surveys in Cameroon and Gabon included six questions useful to grasp levels of exposure to cooking smoke. The first question, "what type of fuel does your household usually use for cooking?", helped classifying households in one of the following twelve categories: electricity, liquid petroleum gas (LPG), natural gas, biogas, kerosene, coal (lignite), charcoal, wood, straw/shrubs/grass, agricultural crop, animal dung, and a residual category. These categories were regrouped to form four groups: low pollution fuels (electricity, liquid petroleum gas (LPG), natural gas, biogas), biomass fuels (wood, straw/shrubs/grass, agricultural crop, animal dung), other known fuels (kerosene, coal (lignite), charcoal). The remaining households formed a residual category, including households using unknown fuels and those where no cooking was done. The discussion did not include this category due to the unknown nature of the fuels used and the small number of households that did no cooking ( $0.04 \%$ in Cameroon).

The indicator used to capture biomass fuel pollution was further improved to reflect the rural context. Data show that very few households in rural areas used only cleaner energy. Rather, a mix of fuels were used by safer households, mainly gas and biomass fuel. Therefore, three main categories were finally obtained: "gas/electricity and/or biomass fuel", "biomass fuel without gas/electricity" and "other fuels". A lower likelihood of ARI among houses using gas and/or biomass fuel compared to those using only biomass fuel would show evidence of the good effect of using cleaner energy.

The main predictor in this study is the type of cooking fuel. Four additional questions were asked to help capture indoor air pollution related to cooking smoke: "Do you cook on open fire, open stove or closed stove?" "Does this fire/stove have a chimney, hood or neither?" "Is the food usually cooked in the house, in a separate building or outdoors?" For households cooking in the house, the following question was asked: "Do you have a separate room used as kitchen?" Since households with closed stoves or chimneys were very few, only the two remaining questions were used to create the variable cooking place: in the house (with a separate room 
used as kitchen), in the house (without a separate room for kitchen), in a separate building or outdoors.

\subsection{Statistical Analysis}

To build a sound statistical model, the association between independent variables was tested to prevent multicolinearity. To ensure no clustering at household level, absence of correlation was ascertained between ARI and household number. Moreover, the variance inflation factor (VIF) was computed for Cameroon (12.77) and Gabon (2.42). Gabon's VIF value being lower than 2.5, the independent variables were adequate for regression analysis. [1] In Cameroon, because of high VIF value, the problematic variable child's sex was dropped from the analysis. Additionally, the chi-square statistic was used for preliminary significance tests of the relationship between the dependent variable and each of the independent variables.

To assess the relationship between cooking fuel and ARI, logistic regression analysis was conducted using the statistical software package Stata. Confounders used to control the effect of cooking fuel on ARI included floor material (earth/sand/dung/planks/bamboo, cement, parquet/polished wood/vinyl, asphalt, other), cooking place (separate room used as kitchen, cooking in the house without separate kitchen, cooking in a separate building, cooking outdoors, other), region of child's residence (Cameroon: Adamaoua, Center, East, Far north, Littoral, North, North West, West, South, South West; Gabon: Estuaire, HautOgooué, Moyen-Ogooué, Ngounié, Nyanga, Ogooué maritime, Ogooué-Ivindo, Ogooué-lolo, Wolo-Ntem), child's age in months $(0-5,6-11,12-23,24-35,36-59)$, mother's age at child's birth in years (15-24, 25-34, 35-49), mother's level of education (no education, primary, secondary, higher), overcrowding measured by the number of persons per room $(<3,3-4,5+)$, birth order $(1,2,3,4+)$, use of healthcare services (public, private, other sector, no treatment), wealth index (poorer, poor, middle, rich), child's nutritional status (stunted, not stunted). The methodology used to obtain the indicator for child's nutritional status is defined in Table 1 footnote.

\section{Results}

Table 1 below summarizes the distribution of children for various characteristics at individual (child), woman, household, and national levels. The statistics are provided for rural areas of Cameroon and Gabon.

While ARI rates among children in Cameroon stand at $5.88 \%$, the rates in Gabon are nearly the double $(9.32 \%)$. However, use of biomass fuel as the only source of domestic energy is virtually universal in rural areas of Cameroon $(93.70 \%)$ while Gabon's rural areas show a significant trend toward mix use of gas and firewood (48.46\%).

Concerning child individual characteristics, Cameroon and Gabon have the same trend for child age, birth order and child nutritional status (stunting is a major problem in both countries). At household level, about half of children in both countries live in household with 3 to 4 members. It appears the two countries are culturally similar, which accounts for the similarity in demographic and healthcare patterns.

Moreover, both countries report variations in the number of children between regions. The rural areas of the Far North (resp. Ogooué-Ivindo) report the highest number of children while the rural areas of Littoral (resp. Ogooué maritime) report the lowest number of children. This may indicate higher urbanization rates in coastal regions.

However, there are differences between the two countries concerning access to medical services, wealth index and mother's education. Although healthcare coverage is low for both countries, more children have access to public medical services in less populated Gabon (36.56\%) than in Cameroon (17.95\%). In Gabon, living standards are higher, but disparities are also higher with a greater proportion of poorer people $(78.07 \%$ versus $35.61 \%)$. Schooling rates are higher in Gabon (only $5.48 \%$ of children were born to unschooled mothers) than in Cameroon (33.41\% of children from unschooled mothers). In a nutshell, there is a stronger trend toward modernization in rural areas of Gabon. 
Table 1. Sample distribution and reported ARI prevalence by selected characteristics, among rural children under five, two weeks prior to CDHS 2011 and GDHS2012.

\begin{tabular}{|c|c|c|c|c|c|c|}
\hline & & & \multicolumn{2}{|c|}{ Sample distribution (\%) } & \multicolumn{2}{|c|}{ ARI prevalence (\%) } \\
\hline & & & $\begin{array}{c}\text { Cameroon } \\
\text { rural }\end{array}$ & $\begin{array}{c}\text { Gabon } \\
\text { rural }\end{array}$ & $\begin{array}{l}\text { Cameroon } \\
\text { rural }\end{array}$ & $\begin{array}{c}\text { Gabon } \\
\text { rural }\end{array}$ \\
\hline \multirow[t]{2}{*}{ Country level } & & & & & 5.88 & 9.32 \\
\hline & & & & & $*(1)$ & $* * *$ \\
\hline \multirow{4}{*}{$\begin{array}{c}\text { Type of cooking } \\
\text { fuel }\end{array}$} & & Electricity/gas and/or biomass fuel & 4.42 & 48.46 & 2.72 & 7.82 \\
\hline & & Other fuels & 1.89 & 5.07 & 4.55 & 17.17 \\
\hline & & Biomass fuel & 93.70 & 46.47 & 6.05 & 10.03 \\
\hline & & & & & ns & ns \\
\hline \multirow{3}{*}{ Floor material } & & earth/sand/dung/planks/bamboo & 73.34 & 55.12 & 6.21 & 9.57 \\
\hline & & cement & 22.21 & 37.65 & 4.87 & 9.12 \\
\hline & & parquet/polished wood/vinyl/asphalt & 4.45 & 7.22 & 5.41 & 8.51 \\
\hline & & & & & ns & ns \\
\hline \multirow{4}{*}{ Cooking place } & & separate room used as kitchen & 7.56 & 17.62 & 5.45 & 9.59 \\
\hline & & cooking in the house without separate kitchen & 6.37 & 9.12 & 4.58 & 7.30 \\
\hline & & cooking in a separate building & 63.48 & 40.78 & 5.66 & 10.80 \\
\hline & & cooking outdoors & 25.59 & 32.48 & 7.00 & 7.89 \\
\hline & & & & & $* * *$ & $* * *$ \\
\hline \multirow{5}{*}{$\begin{array}{l}\text { Child's age } \\
\text { (in months) }\end{array}$} & & $0-5$ & 11.72 & 11.78 & 4.55 & 4.78 \\
\hline & & $6-11$ & 11.58 & 12.60 & 9.05 & 7.32 \\
\hline & & $12-23$ & 22.35 & 22.95 & 6.92 & 10.49 \\
\hline & & $24-35$ & 19.21 & 19.26 & 5.28 & 13.03 \\
\hline & & $36-59$ & 35.15 & 33.40 & 4.94 & 8.74 \\
\hline & & & & & ns & ns \\
\hline \multirow{3}{*}{$\begin{array}{l}\text { Mother's age at } \\
\text { child's birth }\end{array}$} & & $15-24$ & 44.48 & 42.78 & 6.18 & 9.34 \\
\hline & & $25-34$ & 41.32 & 37.09 & 5.53 & 9.25 \\
\hline & & $35-49$ & 14.21 & 20.13 & 5.93 & 9.41 \\
\hline \multirow{4}{*}{$\begin{array}{c}\text { Number of } \\
\text { persons per room }\end{array}$} & & & & & ns & ns \\
\hline & & $<3$ & 30.22 & 32.99 & 6.71 & 10.25 \\
\hline & & $3-4$ & 55.90 & 57.12 & 5.41 & 8.97 \\
\hline & & $5+$ & 13.88 & 9.89 & 5.94 & 8.29 \\
\hline \multirow{5}{*}{ Birth order } & & & & & ns & ns \\
\hline & & 1 & 18.21 & 18.34 & 7.08 & 7.26 \\
\hline & & 2 & 16.87 & 17.83 & 6.21 & 10.34 \\
\hline & & 3 & 14.79 & 14.50 & 5.69 & 10.95 \\
\hline & & $4+$ & 50.13 & 49.33 & 5.38 & 9.24 \\
\hline \multirow{6}{*}{$\begin{array}{l}\text { Use of medical } \\
\text { services }\end{array}$} & & & & & $* * *$ & * \\
\hline & & public & 17.95 & 36.56 & 18.98 & 21.28 \\
\hline & & private & 6.50 & 8.22 & 17.07 & 28.38 \\
\hline & & other sector & 28.22 & 4.43 & 15.73 & 23.08 \\
\hline & & no treatment & 47.32 & 50.89 & 9.55 & 16.38 \\
\hline & & & & & ns & ns \\
\hline \multirow{3}{*}{$\begin{array}{c}\text { Child nutritional } \\
\text { status (2) } \\
\end{array}$} & & Stunted & 73.09 & 85.51 & 5.91 & 9.89 \\
\hline & & Not stunted & 26.91 & 14.49 & 4.48 & 7.61 \\
\hline & & & & & $* * *$ & ns \\
\hline \multirow{4}{*}{ Wealth index } & & Poorer & 35.61 & 78.07 & 6.80 & 9.84 \\
\hline & & Poor & 36.47 & 12.24 & 5.84 & 7.11 \\
\hline & & Middle & 19.53 & 5.84 & 4.05 & 7.02 \\
\hline & & Rich & 5.89 & 2.51 & 7.87 & 10.20 \\
\hline & & & & & ns & ns \\
\hline \multirow{5}{*}{$\begin{array}{l}\text { Mother's } \\
\text { education }\end{array}$} & & no education & 33.41 & 5.48 & 6.17 & 9.35 \\
\hline & & primary & 46.86 & 55.12 & 5.39 & 9.20 \\
\hline & & secondary & 19.19 & 38.47 & 6.54 & 9.59 \\
\hline & & higher & 0.53 & 0.92 & 6.45 & 5.56 \\
\hline & Cameroon rural & Gabon rural & & & $* * *$ & $* *$ \\
\hline & Adamaoua & Estuaire & 9.52 & 11.73 & 4.87 & 8.30 \\
\hline & Center & Haut- Ogooué & 9.74 & 7.68 & 6.35 & 10.00 \\
\hline & East & Moyen-Ogooué & 7.78 & 9.43 & 2.65 & 8.70 \\
\hline & Far north & Ngounié & 19.95 & 14.09 & 6.80 & 9.09 \\
\hline Region of child's & Littoral & Nyanga & 2.77 & 7.48 & 1.24 & 17.12 \\
\hline residence & North & Ogooué maritime & 17.44 & 6.05 & 7.29 & 1.69 \\
\hline & North West & Ogooué-Ivindo & 10.50 & 21.88 & 7.36 & 9.84 \\
\hline & West & Ogooué-lolo & 8.73 & 13.32 & 4.92 & 8.85 \\
\hline & South & Wolo-Ntem & 6.27 & 8.35 & 3.84 & 9.20 \\
\hline & South West & & 7.32 & & 6.57 & \\
\hline
\end{tabular}

(1) Codes for significance levels: ns (not significant), * $(10 \%), * *(5 \%), * * *(1 \%)$

(2) Stunting is a measure of child malnutrition, using linear growth retardation as proxy. Children with height-for-age greater than two standard deviation units below the median of the International Reference Population are defined as stunted. 
Regarding factors linked to household domestic environment, the same trend is discernible, most houses lacking modern floor materials (cement or asphalt) while rural housing typically reserves a separate building for cooking. Still, levels of access to modern floor materials are higher in Gabon (44.87\% versus 26.66\%). Similarly, 63.48\% of children in Cameroon live in households adhering to the rural pattern of cooking in a separate building (compared to $40.78 \%$ in Gabon).

The association between ARI and each of the independent variables leads to similar trends in Cameroon and Gabon. However, levels of ARI rate are always higher in Gabon. ARI rates are lower for children age 0-5 months, higher at intermediate ages, and the rates finally fall for oldest children. The low prevalence at $0-5$ months is usually associated with the natural protection during the breastfeeding period (antibodies contained in mother's milk). The subsequent rise is related to the end of breastfeeding period while the fall witnessed for older children accounts for child immunization. In both countries, children show similar levels of exposure at 0-5 months (between $4.5 \%$ and $5 \%$ ) but ARI prevalence among Cameroonian children picks at 9.05\% (6-11 months) while ARI rates among Gabonese children pick at $13.03 \%$ (24-35 months). Moreover, the chi-square statistic shows the relationship between ARI and child age is significant in Cameroon $(p=0.000)$ and Gabon $(p=0.008)$. Further analysis will be conducted for this variable in the next paragraphs.

Stunted children face higher risk in both countries, but the pattern of ARI according to child birth order is quite different. While in Cameroon ARI occurrence falls as birth rank increases, in Gabon ARI rates pick for children of rank 2 and 3.

Similarly, the trends at household level are broadly similar, with country-specific levels of prevalence. In both countries, the ARI rates for children living in households using only biomass fuel are higher than ARI rates for children living in household using a mix of gas and biomass fuel. However, the highest rates in Gabon (17.17\% for the category "Other fuels") are 3 times higher than the highest rates in Cameroon (6.05\% for the category "Biomass fuel"). The association is significant in Cameroon and Gabon.

In both countries there is a higher level of reported ARI for children born in households visiting healthcare centers and children living in rich households (indication of better reporting in such households). Cooking in a separate building (resp. outdoors) is typical of poorer habitat, thus the association with higher ARI rates in Cameroon (resp. Gabon). In both countries, there is little variation of prevalence according to mother's age at child birth. Smaller households (less than 3 members) report higher rates and children born to mothers with a secondary level of education face a higher risk. Similarly, less populated rural regions near coastal cities show lowest prevalence (Littoral in Cameroon and Ogooué maritime in Gabon). This descriptive analysis needs to be confirmed by the subsequent explanatory analysis. 
Table 2. Odds ratio estimates of effects of cooking fuel and other factors on ARI prevalence among children under five in Cameroon rural (2011).

\begin{tabular}{|c|c|c|c|c|c|}
\hline & & Model 1 & Model 2 & Model 3 & Model 4 \\
\hline & & OR 95\% CI & OR $95 \% \mathrm{CI}$ & OR $95 \%$ CI & OR $95 \% \mathrm{CI}$ \\
\hline $\begin{array}{l}\text { Type of cooking } \\
\text { fuel }\end{array}$ & $\begin{array}{l}\text { Electricity/Gas and/or Biomass fuel }{ }^{\mathrm{a}} \\
\text { Other fuels (1) } \\
\text { Biomass no gas }\end{array}$ & $\begin{array}{c}- \\
\text { (ns) } \mathbf{1 . 7 0}(0.53,5,48) \\
(* *) \mathbf{2 . 3 0}(1.08,4.91)\end{array}$ & $\begin{array}{c}- \\
\text { (ns) } \mathbf{1 . 8 6}(0.30,11.53) \\
(*) \mathbf{3 . 0 7}(0.96,9.80)\end{array}$ & $\begin{array}{c}- \\
\text { (ns) } 3.37(0.44,25.74) \\
(* *) 4.77(1.56,19.67) \\
\end{array}$ & $\begin{array}{c}- \\
\text { (ns) } 4.13(0.51,33.57) \\
(* *) \mathbf{5 . 6 2}(1.29,24.44)\end{array}$ \\
\hline $\begin{array}{l}\text { Child's age (in } \\
\text { months) }\end{array}$ & $\begin{array}{l}0-5^{\mathrm{a}} \\
6-11 \\
12-23 \\
24-35 \\
36-59 \\
\end{array}$ & & $\begin{array}{c}- \\
(* * *) \mathbf{2 . 3 4}(1.25,4.39) \\
\text { (ns) } \mathbf{1 . 5 4}(0.85,2.81) \\
\text { (ns) } \mathbf{1 . 0 2}(0.53,1.96) \\
\text { (ns) } \mathbf{1 . 0 2}(0.56,1.84)\end{array}$ & $\begin{array}{c}- \\
\text { (ns) } \mathbf{1 . 3 0}(0.65,2.61) \\
\text { (ns) } \mathbf{0 . 7 7}(0.40,1.51) \\
\text { (ns) } \mathbf{0 . 5 8}(0.28,1.19) \\
\text { (ns) } \mathbf{0 . 6 4}(0.33,1.24)\end{array}$ & $\begin{array}{c}- \\
\text { (ns) } \mathbf{1 . 2 5}(0.61,2.57) \\
\text { (ns) } \mathbf{0 . 6 9}(0.35,1.37) \\
\text { (*) } \mathbf{0 . 5 3}(0.25,1.12) \\
\text { (ns) } \mathbf{0 . 6 3}(0.32,1.23)\end{array}$ \\
\hline Birth order & $\begin{array}{l}1^{\mathrm{a}} \\
2 \\
3 \\
4+\end{array}$ & & $\begin{array}{c}- \\
\text { (ns) } 0.89(0.53,1.49) \\
\text { (ns) } 0.93(0.55,1.58) \\
\text { (ns) } 0.80(0.52,1.22)\end{array}$ & $\begin{array}{c}- \\
\text { (ns) } \mathbf{0 . 8 1}(0.46,1.42) \\
\text { (ns) } \mathbf{0 . 9 0}(0.48,1.68) \\
\text { (ns) } \mathbf{0 . 5 7}(0.29,1.06)\end{array}$ & $\begin{array}{l}- \\
\text { (ns) } \mathbf{0 . 7 8}(0.44,1.41) \\
\text { (ns) } \mathbf{0 . 9 9}(0.52,1.86) \\
\text { (ns) } \mathbf{0 . 6 5}(0.33,1.27)\end{array}$ \\
\hline $\begin{array}{l}\text { Child nutritional } \\
\text { status }\end{array}$ & $\begin{array}{l}\text { Stunted }^{\mathrm{a}} \\
\text { Not stunted }\end{array}$ & & $\begin{array}{c}- \\
\text { (ns) } 0.78(0.53,1.14)\end{array}$ & $\begin{array}{c}- \\
\text { (ns) } 0.77(0.50,1.16)\end{array}$ & $\begin{array}{c}- \\
\text { (ns) } \mathbf{0 . 7 7}(0.50,1.17)\end{array}$ \\
\hline $\begin{array}{l}\text { Mother's } \\
\text { education }\end{array}$ & $\begin{array}{l}\text { no education }^{\mathrm{a}} \\
\text { primary } \\
\text { secondary } \\
\text { higher }\end{array}$ & & & $\begin{array}{c}- \\
\text { (ns) } \mathbf{0 . 9 0}(0.59,1.38) \\
(*) \mathbf{1 . 6 2}(0.92,2.85) \\
(*) \mathbf{6 . 3 6}(0.75,54.01) \\
\end{array}$ & $\begin{array}{c}- \\
\text { (ns) } \mathbf{1 . 0 4}(0.64,1.70) \\
(* *) \mathbf{2 . 3 3}(1.18,4.60) \\
\text { (ns) } \mathbf{5 . 5 7}(0.58,53.38) \\
\end{array}$ \\
\hline $\begin{array}{l}\text { Mother's age at } \\
\text { child's birth }\end{array}$ & $\begin{array}{l}15-24^{\mathrm{a}} \\
25-34 \\
35-49\end{array}$ & & & $\begin{array}{c}- \\
\text { (ns) } \mathbf{1 . 4 8}(0.90,2.44) \\
\text { (ns) } \mathbf{1 . 7 0}(0.87,3.33) \\
\end{array}$ & $\begin{array}{c}- \\
\text { (ns) } \mathbf{1 . 3 4}(0.79,2.26) \\
\text { (ns) } \mathbf{1 . 5 7}(0.77,3.20)\end{array}$ \\
\hline Wealth index & $\begin{array}{l}\text { Poorer }^{a} \\
\text { Poor } \\
\text { Middle } \\
\text { Rich } \\
\end{array}$ & & & $\begin{array}{c}- \\
\text { (ns) } \mathbf{1 . 0 9}(0.71,1.66) \\
\text { (**) } \mathbf{0 . 4 6}(0.22,0.96) \\
\text { (ns) } \mathbf{1 . 5 1}(0.54,4.22) \\
\end{array}$ & $\begin{array}{c}- \\
\text { (ns) } \mathbf{1 . 0 1}(0.62,1.63) \\
(*) \mathbf{0 . 4 7}(0.21,1.08) \\
\text { (ns) } \mathbf{1 . 7 9}(0.58,5.52) \\
\end{array}$ \\
\hline $\begin{array}{l}\text { Number of } \\
\text { persons per room }\end{array}$ & $\begin{array}{l}<3^{\mathrm{a}} \\
3-4 \\
5+\end{array}$ & & & $\begin{array}{c}- \\
\text { (ns) } 0.77(0.53,1.14) \\
\text { (ns) } \mathbf{1 . 0 1}(0.60,1.72)\end{array}$ & $\begin{array}{c}- \\
\text { (ns) } 0.79(0.53,1.18) \\
\text { (ns) } 0.92(0.54,1.60)\end{array}$ \\
\hline $\begin{array}{l}\text { Use of medical } \\
\text { services }\end{array}$ & $\begin{array}{l}\text { public }^{\mathrm{a}} \\
\text { private } \\
\text { other sector } \\
\text { no treatment }\end{array}$ & & & $\begin{array}{c}- \\
\text { (ns) } \mathbf{1 . 3 1}(0.66,2.62) \\
\text { (ns) } \mathbf{0 . 7 5}(0.47,1.22) \\
(* * *) \mathbf{0 . 3 6}(0.23,0.58)\end{array}$ & $\begin{array}{c}- \\
\text { (ns) } \mathbf{1 . 2 0}(0.58,2.49) \\
\text { (ns) } \mathbf{0 . 8 8}(0.52,1.49) \\
(* * *) \mathbf{0 . 3 8}(0.23,0.61)\end{array}$ \\
\hline Cooking place & $\begin{array}{l}\text { separate room used as kitchen }{ }^{\mathrm{a}} \\
\text { cooking in the house without separate kitchen } \\
\text { cooking in a separate building } \\
\text { cooking outdoors }\end{array}$ & & & $\begin{array}{c}- \\
\text { (ns) } \mathbf{0 . 6 3}(0.25,1.62) \\
(*) \mathbf{0 . 5 6}(0.30,1.05) \\
(\mathrm{ns}) \mathbf{0 . 5 6}(0.28,1.12)\end{array}$ & $\begin{array}{c}- \\
\text { (ns) } \mathbf{0 . 7 5}(0.28,2.04) \\
\text { (ns) } \mathbf{0 . 6 7}(0.33,1.39) \\
\text { (ns) } \mathbf{0 . 8 0}(0.37,1.71)\end{array}$ \\
\hline Floor material & $\begin{array}{l}\text { earth/sand/dung/planks/bamboo }{ }^{\mathrm{a}} \\
\text { cement } \\
\text { parquet/polished wood/vinyl/asphalt }\end{array}$ & & & $\begin{array}{c}- \\
\text { (ns) } \mathbf{0 . 8 3}(0.44,1.58) \\
\text { (ns) } \mathbf{0 . 3 8}(0.11,1.38) \\
\end{array}$ & $\begin{array}{c}- \\
\text { (ns) } \mathbf{0 . 8 1}(0.41,1.60) \\
(*) \mathbf{0 . 3 3}(0.09,1.18) \\
\end{array}$ \\
\hline
\end{tabular}




\begin{tabular}{|c|c|c|c|c|c|}
\hline $\begin{array}{l}\text { Region of child's } \\
\text { residence }\end{array}$ & $\begin{array}{l}\text { Littoral }^{\mathrm{a}} \\
\text { Center } \\
\text { Adamaoua } \\
\text { East } \\
\text { Far north } \\
\text { North } \\
\text { North West } \\
\text { West } \\
\text { South } \\
\text { South West }\end{array}$ & & & - & 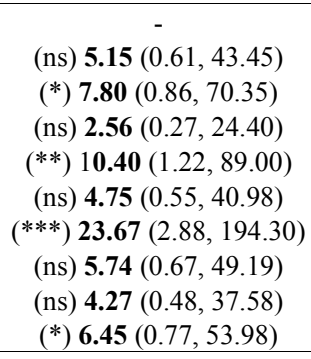 \\
\hline $\begin{array}{l}\text { Number of } \\
\text { children }\end{array}$ & & 5821 & 5821 & 5821 & 5821 \\
\hline
\end{tabular}

a: Reference category; ns: not significant; *: $10 \% ; * *: 5 \% ; * * *: 1 \%$;

Table 3. Odds ratio estimates of effects of cooking fuel and other factors on ARI prevalence among children under five in Gabon rural (2012).

\begin{tabular}{|c|c|c|c|c|c|}
\hline & & Model 1 & Model 2 & Model 3 & Model 4 \\
\hline & & OR 95\% CI & OR $95 \% \mathrm{CI}$ & OR $95 \% \mathrm{CI}$ & OR $95 \% \mathrm{CI}$ \\
\hline Type of cooking fuel & $\begin{array}{l}\text { Electricity/Gas and/or Biomass } \\
\text { fuel }^{\mathrm{a}} \\
\text { Other fuels (1) } \\
\text { Biomass no gas }\end{array}$ & $\begin{array}{c}- \\
(* * *) \mathbf{2 . 4 4}(1.38,4.34) \\
(*) \mathbf{1 . 3 1}(0.95,1.81)\end{array}$ & $\begin{array}{c}- \\
\text { (ns) } \mathbf{1 . 8 2}(0.85,3.93) \\
\text { (ns) } \mathbf{1 . 2 4}(0.85,1.81)\end{array}$ & $\begin{array}{c}- \\
(* * *) \mathbf{3 . 8 3}(1.46,10.05) \\
(* *) \mathbf{1 . 7 3}(1.02,2.96)\end{array}$ & $\begin{array}{c}- \\
(* * *) \mathbf{3 . 9 9}(1.46,10.91) \\
(*) \mathbf{1 . 7 1}(0.98,2.97)\end{array}$ \\
\hline $\begin{array}{l}\text { Child's age (in } \\
\text { months) }\end{array}$ & $\begin{array}{l}0-5^{\mathrm{a}} \\
6-11 \\
12-23 \\
24-35 \\
36-59 \\
\end{array}$ & & $\begin{array}{c}- \\
\text { (ns) } \mathbf{1 . 6 9}(0.65,4.41) \\
(* * *) \mathbf{3 . 1 2}(1.35,7.22) \\
(* * *) \mathbf{3 . 2 3}(1.39,7.48) \\
(* *) \mathbf{2 . 3 1}(1.01,5.26)\end{array}$ & $\begin{array}{c}- \\
\text { (ns) } \mathbf{0 . 7 7}(0.27,2.20) \\
\text { (ns) } \mathbf{1 . 7 2}(0.67,4.38) \\
\text { (ns) } \mathbf{1 . 7 9}(0.70,4.56) \\
\text { (ns) } \mathbf{1 . 6 7}(0.67,4.17) \\
\end{array}$ & 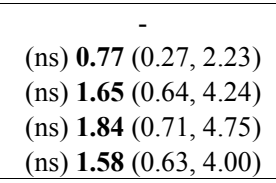 \\
\hline Birth order & $\begin{array}{l}1^{\mathrm{a}} \\
2 \\
3 \\
4+ \\
\end{array}$ & & $\begin{array}{c}- \\
\text { (ns) } \mathbf{1 . 2 8}(0.67,2.43) \\
\text { (ns) } \mathbf{1 . 6 8}(0.88,3.21) \\
\text { (ns) } \mathbf{1 . 1 3}(0.66,1.93) \\
\end{array}$ & $\begin{array}{c}- \\
(\mathrm{ns}) \mathbf{1 . 3 2}(0.64,2.74) \\
(* * *) \mathbf{2 . 9 8}(1.34,6.62) \\
(\mathrm{ns}) \mathbf{2 . 0 4}(0.87,4.78) \\
\end{array}$ & $\begin{array}{c}- \\
\text { (ns) } \mathbf{1 . 2 9}(0.62,2.70) \\
(* * *) \mathbf{3 . 0 5}(1.35,6.86) \\
(*) \mathbf{2 . 1 7}(0.91,5.20)\end{array}$ \\
\hline $\begin{array}{l}\text { Child nutritional } \\
\text { status }\end{array}$ & $\begin{array}{l}\text { Stunted }^{\mathrm{a}} \\
\text { Not stunted }\end{array}$ & & $\begin{array}{c}- \\
\text { (ns) } 0.74(0.42,1.30)\end{array}$ & (ns) $0.90(0.48,1.70)$ & (ns) $0.92(0.48,1.76)$ \\
\hline Mother's education & $\begin{array}{l}\text { no education }^{\mathrm{a}} \\
\text { primary } \\
\text { secondary } \\
\text { higher }\end{array}$ & & & $\begin{array}{c}- \\
\text { (ns) } 0.55(0.21,1.38) \\
\text { (ns) } 0.72(0.27,1.88) \\
\text { (ns) } 0.47(0.03,6.79)\end{array}$ & $\begin{array}{c}- \\
\text { (ns) } \mathbf{0 . 5 1}(0.20,1.34) \\
\text { (ns) } \mathbf{0 . 7 9}(0.29,2.15) \\
\text { (ns) } \mathbf{0 . 3 5}(0.02,5.22)\end{array}$ \\
\hline $\begin{array}{l}\text { Mother's age at } \\
\text { child's birth }\end{array}$ & $\begin{array}{l}15-24^{\mathrm{a}} \\
25-34 \\
35-49\end{array}$ & & & $\begin{array}{c}- \\
\text { (*) } \mathbf{0 . 5 5}(0.28,1.06) \\
\text { (ns) } \mathbf{0 . 6 0}(0.27,1.34)\end{array}$ & $\begin{array}{c}- \\
\text { (**) } \mathbf{0 . 5 0}(0.25,1.00) \\
\text { (ns) } \mathbf{0 . 5 3}(0.23,1.21)\end{array}$ \\
\hline
\end{tabular}




\begin{tabular}{|c|c|c|c|c|c|}
\hline Wealth index & $\begin{array}{l}\text { Poorer }^{\mathrm{a}} \\
\text { Poor } \\
\text { Middle } \\
\text { Rich } \\
\end{array}$ & & & $\begin{array}{c}- \\
\text { (ns) } \mathbf{0 . 6 1}(0.27,1.37) \\
\text { (ns) } \mathbf{0 . 6 5}(0.22,1.90) \\
\text { (ns) } \mathbf{1 . 0 4}(0.24,4.51) \\
\end{array}$ & $\begin{array}{c}- \\
\text { (ns) } \mathbf{0 . 6 6}(0.29,1.54) \\
\text { (ns) } \mathbf{0 . 7 5}(0.24,2.29) \\
\text { (ns) } \mathbf{1 . 1 3}(0.25,5.17) \\
\end{array}$ \\
\hline $\begin{array}{l}\text { Number of persons } \\
\text { per room }\end{array}$ & $\begin{array}{l}<3^{\mathrm{a}} \\
3-4 \\
5+ \\
\end{array}$ & & & $\begin{array}{l}- \\
\text { (ns) } \mathbf{0 . 7 9}(0.50,1.25) \\
\text { (ns) } \mathbf{1 . 0 3}(0.49,2.15) \\
\end{array}$ & $\begin{array}{c}- \\
\text { (ns) } 0.79(0.50,1.26) \\
\text { (ns) } \mathbf{0 . 8 6}(0.40,1.84) \\
\end{array}$ \\
\hline $\begin{array}{l}\text { Use of medical } \\
\text { services }\end{array}$ & $\begin{array}{l}\text { public }^{\mathrm{a}} \\
\text { private } \\
\text { other sector } \\
\text { no treatment }\end{array}$ & & & $\begin{array}{c}- \\
\text { (ns) } \mathbf{1 . 2 7}(0.60,2.68) \\
\text { (ns) } \mathbf{0 . 9 7}(0.34,2.78) \\
(* * *) \mathbf{0 . 5 2}(0.33,0.83) \\
\end{array}$ & $\begin{array}{c}(\mathrm{ns}) \mathbf{1 . 0 0}(0.46,2.16) \\
(\mathrm{ns}) \mathbf{0 . 9 0}(0.30,2.63) \\
(* * *) \mathbf{0 . 5 1}(0.32,0.83)\end{array}$ \\
\hline Cooking place & $\begin{array}{l}\text { separate room used as kitchen } \\
\text { cooking in the house without } \\
\text { separate kitchen } \\
\text { cooking in a separate building } \\
\text { cooking outdoors }\end{array}$ & & & $\begin{array}{c}- \\
\text { (ns) } 0.81(0.29,2.26) \\
\text { (ns) } \mathbf{1 . 2 8}(0.63,2.58) \\
\text { (ns) } \mathbf{1 . 0 1}(0.48,2.13)\end{array}$ & $\begin{array}{l}- \\
\text { (ns) } \mathbf{1 . 0 1}(0.35,2.89) \\
\text { (ns) } \mathbf{1 . 2 8}(0.60,2.72) \\
\text { (ns) } \mathbf{1 . 3 7}(0.70,3.01)\end{array}$ \\
\hline Floor material & $\begin{array}{l}\text { earth/sand/dung/planks/bamboo }{ }^{\mathrm{a}} \\
\text { cement } \\
\text { parquet/polished } \\
\text { wood/vinyl/asphalt }\end{array}$ & & & $\begin{array}{c}- \\
\text { (ns) } 0.91(0.56,1.49) \\
\text { (ns) } 1.97(0.73,5.31)\end{array}$ & $\begin{array}{c}- \\
\text { (ns) } \mathbf{0 . 8 9}(0.53,1.49) \\
\text { (ns) } \mathbf{1 . 8 0}(0.65,4.97)\end{array}$ \\
\hline $\begin{array}{l}\text { Region of child's } \\
\text { residence }\end{array}$ & $\begin{array}{l}\text { Ogooué-lolo } \\
\text { Estuaire } \\
\text { Haut- Ogooué } \\
\text { Moyen-Ogooué } \\
\text { Ngounié } \\
\text { Nyanga } \\
\text { Ogooué maritime } \\
\text { Ogooué-Ivindo } \\
\text { Wolo-Ntem } \\
\end{array}$ & & & - & $\begin{array}{c}- \\
(* *) \mathbf{2 . 6 6}(1.01,7.00) \\
(* *) \mathbf{2 . 8 5}(1.02,7.93) \\
(\mathrm{ns}) \mathbf{2 . 1 1}(0.78,5.71) \\
(*) \mathbf{2 . 4 1}(0.94,6.17) \\
(* *) \mathbf{5 . 4 6}(1.94,15.35) \\
(\mathrm{ns}) \mathbf{1 . 9 9}(0.34,11.58) \\
(* *) \mathbf{2 . 4 5}(1.01,5.97) \\
(\mathrm{ns}) \mathbf{1 . 5 8}(0.56,4.44)\end{array}$ \\
\hline Number of children & & 1952 & 1952 & 1952 & 1952 \\
\hline
\end{tabular}

a: Reference category; ns: not significant; *: $10 \%$;**: $5 \%$;**: $1 \%$; 
In Cameroon (Table 2) and Gabon (Table 3), the crude and adjusted odds ratios of having suffered from ARI were estimated. In both countries, children living in rural households using only biomass fuel were more likely to have suffered from ARI than children living in rural households using a mix of gas and biomass fuel. In Model 1, children from households using only biomass fuel were 2.30 times (resp. 1.31 time) more likely to have suffered from ARI than children in the reference group in Cameroon (resp. Gabon). The association was significant at the level of $5 \%$ in Cameroon and $10 \%$ in Gabon. After adjusting for individual characteristics of children (child age, birth order, nutritional status) in Model 2, the magnitude of the relationship increases in Cameroon, children from the target group being 3.07 times more likely to suffer from ARI. In Model 2, the effect of biomass fuel remains significant only in Cameroon. This shows the role of child characteristics in Gabon as intermediate variables helping to understand the mechanism leading to ARI occurrence. When further controlling for mother and household variables (mother education, mother age at child birth, wealth index, number of persons per room, use of medical services, cooking place, and floor material) in Model 3, the effect of biomass fuel sharpens further in Cameroon with a significant odds ratio of 4.77. In Gabon, the odds ratio increases to 1.73 and the relationship becomes significant. In the full model (Model 4), as child region of residence is controlled, the relationship sharpens further in Cameroon. Children from biomass fuel using households are 5.62 times more likely to have suffered from ARI than their counterparts from rural households using a mix of gas and biomass fuel. The relationship remains significant in both countries. In Gabon, the effect of other fuels (charcoal, kerosene) appears even more significant (at the level of 1\%) and large (odds ratio equals 2.44 in the unadjusted model while rising to 3.99 in the full model).

After adjusting for all confounders, ten variables other than the main predictor remained significant in Cameroon and/or in Gabon. The variables "use of medical services" and "region" was significant in both full models. In Gabon, children living in rural areas in the regions "Estuaire", "Haut-Ogooué", "Ngounié", "Nyanga" and "Ogooué-Ivindo" were all more likely to have suffered from ARI than children living in rural areas of "Ogooué-lolo". The highest risk is faced by children from the region "Nyanga". They are 5.46 times more likely to have suffered from ARI than those from the reference group.

In Cameroon, children living in rural areas in the regions "Adamaoua", "Far north", "North West", "South West" were more exposed than children from rural areas of "Littoral". Specifically, children from the North West region presented a particularly high rate of exposure. They were 23.67 times more likely to have suffered from ARI than those from the reference group, with a significance level at $1 \%$. Therefore, regional variations in ARI risk are more striking in Cameroon than in Gabon. This could account for the fact that Cameroon's territory is much larger than Gabon's, thus the higher dispersion of the population across various climatic zones. In fact, the North West region is characterized by high altitude and severe cold. The three other regions at risk ("Adamaoua", "Far North" and "South West") are also known for experiencing cold seasons in the year. In this regard, previous studies have evidenced a relationship between climate/seasonality and ARI occurrence. Gardinassi [9] observed that ARI was associated with cold and dry seasons in the southeast of Brazil.

The two countries show similar patterns as far as use of medical services is concerned. People who attend public hospitals are twice as likely to have suffered from ARI as those who take no treatment in Cameroon and Gabon. The relationship is significant at the level of $1 \%$ after controlling for all confounders. This is indication that children presented as healthy could experience early symptoms of ARI not readily detected by respondents. On the other hand, people usually attend public hospitals only when the case becomes severe. Various factors may account for delays between the time of sickness occurrence and the time when one receives medical attention: the distance to healthcare facilities, the availability of financial resources for transportation and medicine and the long list of patients already having appointments with physicians in public hospitals.

Cameroon and Gabon differ for the remaining significant variables. In Gabon, mother's age and birth order are significant while in Cameroon child age, mother's education, floor material and wealth index remain significant in the full model. Children in the age bracket 0-5 months in rural areas of Cameroon are twice as likely to have suffered from ARI as children of 24-35 months. This finding sharpens the result obtained in the cross-tabulation analysis above, where the lower risk from children of age $0-5$ months was justified by the protection offered by breastfeeding and the absence of contaminated food. The finding shows that Cameroon rural children in the age group 24-35 months face the lowest risk, thus stressing the role of child immunization. Therefore, children at risk in such areas are those of age 6-23 months.

Children born to mothers of secondary educational level in rural areas of Cameroon are 2.23 times more exposed to ARI than children from unschooled mothers. The relationship is statistically significant at the level of 5\%. Given the fact that schooling rates in Cameroon seriously drop after the primary cycle, it is safe to conclude that women of secondary education typically did not complete their secondary cycle. Furthermore, such women were under trying circumstances when quitting school, as they often suffered the aftermath of unwanted pregnancies. All these factors could explain the higher exposition of their children to ARI.

Floor material is another significant factor behind the occurrence of ARI among rural children in Cameroon. Children from households without floor material are nearly 
3 times more likely to have suffered from ARI than those from households with modern floor materials (parquet, polished wood, vinyl, asphalt). Due to crawling, little children may be in regular contact with floor material, thus their higher exposition, especially during dry seasons when dusty floors significantly contribute to domestic pollution in rural areas.

In Cameroon, children from middle income families are twice less likely to have suffered from ARI compared to children from poorer families. This may reflect the fact that inequalities are less pronounced in Cameroon than in Gabon, Cameroon's middle income class forming a sizable segment in the population.

In Gabon, there are higher risks for rural children of rank 3 and 4+. A woman's third child is 3.05 times more likely to have suffered from ARI than the firstborn. The relationship is significant at the level of $1 \%$. This could give evidence of demographic pressure at household level, larger families facing more difficulties to take care of additional newborn babies. Moreover, children born to younger mothers (15-24 years) in rural areas of Gabon are more exposed. They are twice more likely to have suffered ARI than children from mothers age 25-34 years. This may reflect risks associated with teen pregnancy, as similar risks were pointed out for women of secondary education in Cameroon.

\section{Discussion}

From this comparative analysis of the effect of biomass fuel on child ARI in rural areas of Cameroon and Gabon, it is safe to conclude that the study hypothesis was verified in both countries: rural children from households using only biomass fuel are more exposed to ARI than their counterparts from households using a mix of gas and biomass fuel. This finding underscores the positive effect of gas as cooking fuel. The result is consistent with previous studies conducted in other African countries [2] [3] [10]. The causal relationship evidenced in a follow-up study in Kenya helped to identify $\mathrm{PM}_{10}$ (one of the major pollutants emitted by biomass smoke) as the agent provoking ARI [2].

However, this comparative study went further to reveal country level peculiarities. First, ARI prevalence is much higher in Gabon. However, in Cameroon, the strength of the relationship between biomass fuel and child ARI is three times stronger. This may result from the much higher proportion of biomass fuel users in rural areas of Cameroon. While biomass fuel appears as a key determinant of child ARI in rural areas of Cameroon, other fuels (mainly charcoal) are the main cooking-fuel-related risk factor in Gabon. This suggests that the higher prevalence in Gabon is related to high toxicity of charcoal fuel. In fact, the cross-tabulation analysis conducted above showed that ARI rate was $17.17 \%$ for children of other fuels users, nearly double the rate for all rural children in Gabon. Therefore, use of highly toxic charcoal as cooking fuel could lead to severe pollution, not only in the household, but also in the neighborhood. In other words, use of a particularly toxic type of charcoal could be the factor behind higher morbidity rates among Gabonese children.

Furthermore, the DHS VI surveys used in this study made it possible to improve detection of ARI in children, by adding a question concerning pains in the chest (indicating presence of pneumonia), thus improving the reliability of our findings for policy making.

Some limitations could be raised concerning the results of this study. First, a selection effect due to ARI-related mortality was possible since children from generations $0-4$ years affected by ARI were more likely to have died before the survey than children not affected. The dead children evidently came from poorer households using biomass fuel thus intruding some bias. Nevertheless, the bias would mean that dead children were more exposed to child morbidity. In other words, the effect of biomass fuel on ARI had been underestimated, thus reinforcing our assumption of strong relationship between biomass fuel and ARI. Second, underreporting from less educated mothers using biomass fuel and more likely to have sick children could cause underestimation of cooking fuel effect on ARI. Again, this bias would rather reinforce our conclusions.

Third, no direct measurement was conducted to estimate presence of ARI in children or pollution levels in households using biomass fuel or cleaner fuels. Thus, the study relied on reported occurrence of ARI and reported use of gas or biomass fuel. However, the causal relationship previously evidenced in the follow-up study in Kenya clears any doubt regarding the causal relationship between biomass fuel use and ARI occurrence. Finally, it was not possible with DHS surveys data to distinguish between upper and lower acute respiratory infections.

\section{Conclusions}

Country specific results from this study can be used for policy making at country level since the study relied on large national representative samples. On the other hand, similarities found in the relationship between biomass fuel and ARI are relevant for regional organizations operating in the CEMAC region, as these generally design broad policies implemented throughout countries within the region under their mandate. Thus, organizations like CEMAC, WHO, UNICEF, Plan International, and UNDP could raise awareness on the dangers of biomass fuel use through educational messages in primary and secondary school lessons, radio or TV programs, promotional tea-shirts, caps, umbrellas etc. The target group for this health communication plan is made up of children falling in the categories defined by the significant risk factors identified in the full model.

At country, specific level, governmental health agencies can tackle issues of interest identified in each country. In Cameroon, the use of biomass fuel is virtually universal in 
rural areas. It is therefore necessary to design health programs aiming to distribute LPG cookers to rural households. In Gabon, LPG use is more common, but households using charcoal pose a risk to their neighborhoods. Therefore, gas cookers should be distributed to households using charcoal. It should be noted that the target group is not the same in each country.

In Cameroon, the group at risk is made up of rural children from poorer households, living in the North West region, within the age group 6-23 months, from mothers of secondary level education living in houses without floor material. In rural areas of Gabon, health interventions would target rank 3 children from the region Nyanga, born to mothers within the age group 15-24 years.

From a much broader perspective, it is interesting to signal that the issue of indoor air pollution in Cameroon and Gabon should have support, not only from government health agencies, but also from environmental agencies. For a fact, as demographic growth in African countries remains strong, the number of biomass fuel users is expected to increase. Since forest resources are limited, demographic growth translates into increasing pressure on forest resources, especially wood used as biomass fuel. In turn, pressure on the forest could accentuate climate change. Therefore, mitigation of threats to the environment should lead the international community to support efforts aiming to adapt communities' lifestyles regarding the use of alternative, cleaner domestic energy such as LPG.

\section{REFERENCES}

[1] Mitchell H. Katz. Multivariable Analysis A Practical Guide for Clinicians and Public Health researchers, 3 ed.: Cambridge University Press; 2011.

[2] Ezzati M., Kammen D. Indoor air pollution from biomass combustion and acute respiratory infections in Kenya: an exposure-response study. Lancet 2001; 358(9287): 619-624.

[3] Vinod Mishra. Indoor air pollution from biomass combustion and acute respiratory illness in preschool age children in Zimbabwe. International Journal of Epidemiology 2003; 32(5): 847-853.

[4] Larson BA, Rosen S. Understanding household demand for indoor air pollution control in developing countries. Social Science \& medicine 2002; 55(4): 571-584.

[5] Bruce N, Perez-Padilla R, Albalak R. Indoor air pollution in developing countries: a major environmental and public health challenge. Bull World Health Organ 2000; 78(9): 1078-1092.

[6] R Albalak, A R Frisancho, G J Keeler. Domestic biomass fuel combustion and chronic bronchitis in two rural Bolivian villages. Thorax 1999; 54(11): 1004-1008.
[7] Albalak R. Cultural Practices and Exposure to Particulate Pollution from Indoor Biomass Cooking: Effects on Respiratory Health and Nutritional Status among the Aymara Indians of the Bolivian Highlands [PhD Thesis]. Ann Arbor, Michigan: University of Michigan; 2007.

[8] Smith KR, Samet JM, Romieu I, Bruce N. Indoor air pollution in developing countries and acute lower respiratory infections in children. Thorax 2000; 55(6): 518-532.

[9] Luiz Gustavo Gardinassi, Paulo Vitor Marques Simas, João Batista Salomão, Edison Luiz Durigon, Dirce Maria Zanetta Trevisan, José Antonio Cordeiro, Mauricio Nogueira Lacerda, Paula Rahal, Fátima Pereira de Souz. Seasonality of viral respiratory infections in southeast of Brazil: the influence of temperature and air humidity. Brazil Journal of Microbiology 2012; 43(1): 98-108.

[10] Kilabuko J.H., Nakai S. Effects of Cooking Fuels on Acute Respiratory Infections in Children in Tanzania. International Journal of Environmental Research and Public Health 2007; 4(4): 240-8501.

[11] National Institute of Statistics (INS) Cameroon and Macro International Inc. Cameroon Demographic and Health Survey 2011. Calverton, MD: Central Statistical Office and Macro International Inc; 2011.

[12] National Institute of Statistics (INS) Cameroon and Macro International Inc. Cameroon Demographic and Health Survey 2004. Calverton, MD: Central Statistical Office and Macro International Inc; 2004.

[13] General Directorate of Statistics (DGS) Gabon and Macro International Inc. Gabon Demographic and Health Survey 2000. Calverton, MD: Central Statistical Office and Macro International Inc; 2000.

[14] General Directorate of Statistics (DGS) Gabon and Macro International Inc. Gabon Demographic and Health Survey 2012. Calverton, MD: Central Statistical Office and Macro International Inc; 2012.

[15] United Nations Population Fund (UNFPA). The Power of 1.8 Billion: Adolescents, Youth and the Transformation of the Future. State of World Population Report; 2014.

[16] World Bank. Indoor Air Pollution, Health and the Burden of Disease. Indoor Air Thematic Briefing 2000.

[17] UNICEF MICS. Designing the questionnaire. http://mics.unicef.org (accessed 6 December 2015).

[18] World Bank. Gabon Overview. http://www.worldbank.org/e n/country/gabon/overview (accessed 27 December 2015).

[19] World Bank. Cameroon Overview. http://www.worldbank.or g/en/country/cameroon/overview (accessed 27 December 2015).

[20] World Bank. GDP per capita. http://data.worldbank.org/indicator/NY.GDP.PCAP.CD/cou ntries (accessed 27 December 2015)

[21] Global Conscience Initiative. History of Cameroon. http://gci-cameroon.org/about-cameroon/history-of-cameroo $n$ (accessed 27 December 2015) 